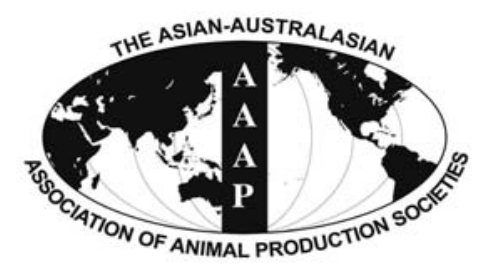

Asian-Aust. J. Anim. Sci.

Vol. 23, No. 1 : 106 - 115

January 2010

www.ajas.info

\title{
Oral Administration of Phosphorylated Dextran Regulates Immune Response in Ovalbumin-Immunized Mice
}

\author{
Chiho Nagasawa, Junko Nishimura-Uemura*, Masanori Tohno ${ }^{1}$, Takeshi Shimosato², Yasushi Kawai, \\ Shuji Ikegami ${ }^{3}$, Munehiro Oda ${ }^{3,4}$, Tadao Saito and Haruki Kitazawa \\ Food Immunology Group, Laboratory of Animal Products Chemistry, Graduate School of Agricultural Science, \\ Tohoku University, Aoba-ku, Sendai 981-8555, Japan
}

\begin{abstract}
Phosphorylated dextran (P-Dex) is an acidic polysaccharide that functions as an immune adjuvant. P-Dex is known to regulate immune response by maintaining a balance between Th1 and Th2 cells in vitro, and thus may also be important in the control of allergic reactions. In the current study, we report the optimum conditions required for the efficient phosphorylation of dextran without toxicity. We found that when dextran was heated at $160^{\circ} \mathrm{C}$ for $24 \mathrm{~h}$ in phosphate buffer (pH 5.0), the resulting P-Dex demonstrated the highest phosphorus content (6.8\%). We also report that P-Dex enhances mitogenic activity in mouse splenocytes and induces expression of CD69 and CD86 on the surface of B cells and dendritic cells (DC) in vitro. Oral administration of P-Dex to ovalubmin (OVA)immunized mice was found to reduce antigen-induced cell proliferation and suppress the expression of CD86 on Th2-inducing DC via exogenous OVA stimulation. P-Dex was also found to increase IL-10 expression in the splenocytes of treated mice. These findings suggest that oral administration of P-Dex increases immunological tolerance and improves the specificity of immunological response to specific antigens. (Key Words : Polysaccharide, Phosphorylated Dextran, Dendritic Cells, Immunoregulation, Allergy, Th1/Th2 Balance)
\end{abstract}

\section{INTRODUCTION}

Lactic acid bacteria (LAB)-mediated immunoregulation depends on the contact of the bacterial components with the gut-associated lymphoid tissue (GALT) (Colbère-Garapin et al., 2007). We have previously identified that an acidic polysaccharide (APS) isolated from a yogurt starter strain of Lactobacillus delbrueckii subsp. bulgaricus serves as a functional bacterial component (Kitazawa et al., 1998; Uemuraet al., 1998), and exerts beneficial immunological

\footnotetext{
* Corresponding Author: Junko Nishimura-Uemura. Tel: +81-22717-8713, Fax: +81-22-717-8715, E-mail: juemura@bios.tohoku. ac.jp

${ }^{1}$ National Agriculture and Food Research Organization, National Institute of Livestock and Grassland Science, Nasushiobara, Tochigi 329-2793, Japan.

2 Fiber-Nanotech Young Researcher Empowerment Center, Shinshu University, Minamiminowa, Kamiina 399-4598, Japan.

${ }^{3}$ Food Science Institute, Meiji Dairies Corporation, Odawara 250-0862, Japan.

4 Laboratory of Food Engineering, College of Bioresource Science, Nihon University, Fujisawa 252-8510, Japan.

Received December 4, 2008; Accepted July 10, 2009
}

effects including the enhancement of lymphocyte mitogenicity (Kitazawa et al., 1998) and macrophage function (Kitazawa et al., 2000; Nishimura-Uemura et al., 2003). However, these beneficial effects are dramatically reduced when APS is dephosphorylated (Kitazawa et al., 2000).

Chemically phosphorylated dextran (P-Dex) has been shown to mimic the immunoregulatory activity of APS (Sato et al., 2004). In addition, P-Dex has been found to contain a pathogen-associated molecular pattern (PAMP) that triggers B cell proliferation, the production of cytokines, antitumor activity and dendritic cell (DC) maturation in splenocytes (Kitazawa et al., 1992, 1998, 2000; Sato et al., 2004). In the current study, we adapted a previously reported method for the chemical phosphorylation of dextran to P-Dex with a phosphorus content of $1.7 \%$ in Leuconostoc mesenteroides (Sato et al., 2004). Prior to the establishment of this method, APS was synthesized using formamide and triethylamine, which restricts its usefulness in both food and medical applications. In this study, we report various conditions that improve the safety and phosphorylation efficiency of P-Dex, and reveal its effects on the immune system following oral administration. In 
order to further our understanding of the effects of P-Dex, various immune responses were monitored in whole splenocyte preparations with and without co-administration of ovalbumin (OVA). Splenocytes were chosen on the basis of earlier studies that showed that the response of this cell population reflects the effects of immunity induced by PDex in vivo (Ito et al., 2005).

\section{MATERIALS AND METHODS}

\section{Chemical phosphorylation and purification of P-Dex}

Food grade dextran (Dex, $40 \mathrm{kDa}$ molecular mass) was purchased from Wako Pure Chemicals (Osaka, Japan). Dex was dispersed in $0.1 \mathrm{M}$ phosphate buffer (PB, $\mathrm{pH} 4.5,5.0$, $5.5,6.0,7.0$ or 8.0 ) at a concentration of $20 \mathrm{mg} / \mathrm{ml}$ and stirred in a water bath at $70^{\circ} \mathrm{C}$ for $30 \mathrm{~min}$ to ensure that it was completely dissolved. The solution was then lyophilized and the lyophilized powder heated at $80^{\circ} \mathrm{C}$ for $48 \mathrm{~h}$ or $100^{\circ} \mathrm{C}, 120^{\circ} \mathrm{C}, 140^{\circ} \mathrm{C}$ or $160^{\circ} \mathrm{C}$ for $24 \mathrm{~h}$ on a heating block. After re-suspension in distilled water, the sample was then dialyzed against distilled water at $4^{\circ} \mathrm{C}$ for $48 \mathrm{~h}$ and lyophilized to produce crude P-Dex. The crude PDex was purified by anion exchange chromatography using a DEAE-Toyopearl $650 \mathrm{M}$ column $(1.6 \mathrm{~cm} \times 15 \mathrm{~cm}$; Tosoh, Tokyo, Japan) and eluted in a linear gradient of 0 to $1.0 \mathrm{M}$ $\mathrm{NaCl}$ in $50 \mathrm{mM}$ Tris-HCl buffer ( $\mathrm{pH}$ 8.6) as previously described (Sato et al., 2004). The fraction that adsorbed to the column was collected as pure P-Dex and the phosphorus content determined using the method of Fiske and SubbaRow, and $\mathrm{KH}_{2} \mathrm{PO}_{4}$ as a standard (Dittmer and Wells, 1969). All P-Dex preparations were tested for endotoxin contamination using the Limulus amoebocyte lysate assay (Seikagaku, Tokyo, Japan).

\section{Animal handling and mouse strains}

Five-week-old pathogen-free male BALB/c mice were purchased from Japan SLC (Shizuoka, Japan) and housed under normal temperature- and light-controlled conditions. A standard diet consisting of 'Labo MR Breeder Pellets' (Nihon Nosan Co., Kanagawa, Japan) and sterile water were supplied ad libitum, and mice were used between 6 and 10 weeks of age. All mice were maintained in accordance to the animal care and use guidelines of Tohoku University.

\section{Mitogenic assay}

Mitogenic activity was measured in mouse splenocytes using the ${ }^{3} \mathrm{H}$-thymidine incorporation method described previously (Kitazawa et al., 1992). ${ }^{3} \mathrm{H}$-thymidine was purchased from Amersham Japan (Tokyo, Japan) for these experiments. The stimulation index (SI) was calculated as follows: SI $=$ (counts per minute $(\mathrm{cpm})$ in treated cellsbackground $\mathrm{cpm}) /(\mathrm{cpm}$ in control cells-background $\mathrm{cpm})$, and the mitogenic characteristics of P-Dex examined as previously described (Sato et al., 2004). Briefly, splenocytes were incubated with biotinylated rat anti-mouse CD45R (Caltag Laboratories, Burlingame, CA, USA) for $30 \mathrm{~min}$ at $4^{\circ} \mathrm{C}$. CD45R ${ }^{+}$cells were isolated by positive selection on a $\mathrm{MS}^{+}$column using a Magnetic Cell Sorting System (Miltenyi Biotec, Gladbach, Germany). The purity of each fraction was then determined using a FACScalibur ${ }^{\mathrm{TM}}$ cell sorter (Becton-Dickinson, Franklin Lakes, NJ, USA). The $\mathrm{CD}_{45 \mathrm{R}^{+}}$fraction was greater than $90 \%$, whereas the $\mathrm{CD}_{45 \mathrm{R}^{-}}$fraction contained less than $3 \%$. The separated $\mathrm{CD}_{45 \mathrm{R}^{+}}$(B cell fraction) and CD45R- (T cell fraction) cells were used for mitogenic assays.

\section{Analysis of cell surface antigens}

Following stimulation with $200 \mu \mathrm{g} / \mathrm{ml} \mathrm{P-Dex}$, at least $1 \times 10^{6}$ splenocytes were sequentially incubated in the following combinations of antibodies (Abs): i) fluorescein isothiocyanate (FITC)-conjugated Armenian hamster antimouse CD69 Ab (BD Pharmingen, San Diego, CA, USA), phycoerythrin (PE)-conjugated rat anti-mouse CD45R Ab and biotinylated monoclonal anti-mouse Thy1.2 Ab (Caltag Laboratories); or ii) PE-conjugated rat anti-mouse CD86 Ab (Caltag Laboratories), biotinylated Armenian hamster antimouse CD11c Ab (BD Pharmingen), and FITC-conjugated rat anti-mouse CD8 $\alpha \mathrm{Ab}$ (Serotec Ltd., Kidlington, UK) for $30 \mathrm{~min}$ at $4^{\circ} \mathrm{C}$ in the dark and then immunostained with PECy5-conjugated streptavidin for anti-Thy $1.2 \mathrm{Ab}$ or antiCD11c Ab (eBioscience, San Diego, CA, USA). After washing twice in wash buffer containing phosphatebuffered saline (PBS), $2 \%$ fetal calf serum and $0.01 \% \mathrm{NaN}_{3}$, cells were fixed in 1\% paraformaldehyde for $15 \mathrm{~min}$. Expression of cell surface antigens was analyzed with a FACScalibur $^{\mathrm{TM}}$ using CELLQuest software (BD Biosciences).

\section{Real-time quantitative PCR}

Cytokine expression was analyzed using the LightCycler real-time PCR system (Roche Diagnostics $\mathrm{GmbH}$, Mannheim, Germany) as previously described (Shimosato et al., 2003; Tohno et al., 2007a). PCR was performed under the following conditions: initial denaturation at $95^{\circ} \mathrm{C}$ for $10 \mathrm{~min}$, followed by 40 cycles of $95^{\circ} \mathrm{C}$ for $15 \mathrm{~s}$ (denaturation), $55^{\circ} \mathrm{C}$ (for IL-10) or $60^{\circ} \mathrm{C}$ (for $\beta$-actin, IL-12p40 and IFN- $\gamma$ ) for $10 \mathrm{~s}$ (annealing), and $72^{\circ} \mathrm{C}$ for $5 \mathrm{~s}$ (extension). Amplification was monitored by measuring fluorescence at the end of each annealing period. The amount of cDNA was calculated from the fluorescence during the log-linear phase of the PCR according to the manufacturer's standard protocol. The primers used for the PCR were as follows: $\beta$-actin (148 bp), 5'- AGA GGG AAA TCG TGC GTG AC and 3'- CAA TAG TGA TGA CCT GGC CGT (Lehmann et al., 2001); IL-10 (73 bp), 5'- TTT 


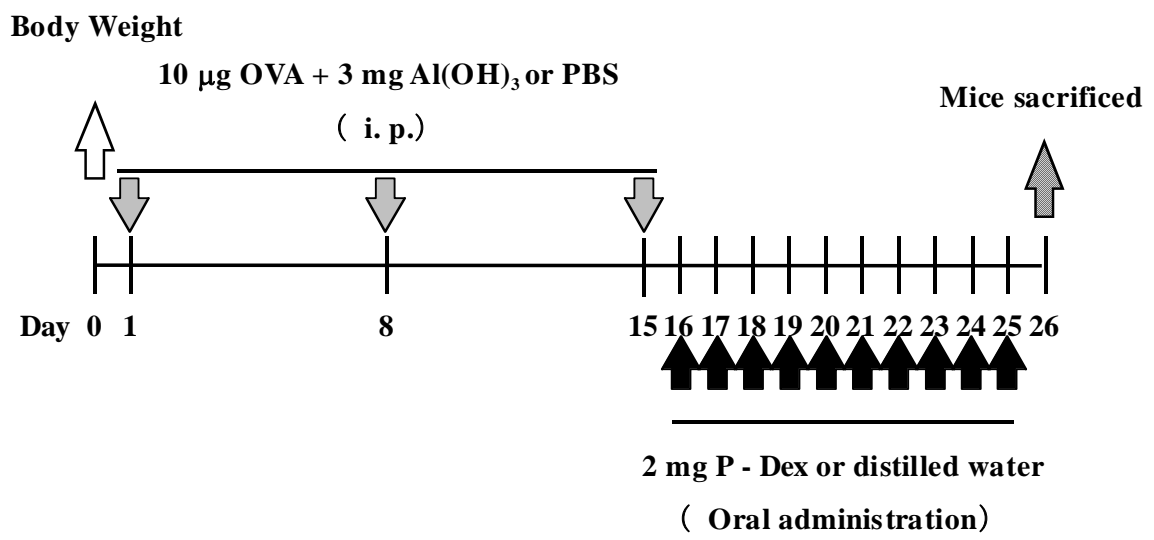

Figure 1. The ovalbumin immunization and P-Dex oral administration schedule. Mice were divided into three groups: i) M1 (OVA(-)/PDex(-)), ii) M2 (OVA(+)/P-Dex(-)) and iii) M3 (OVA(+)/P-Dex(+)). The mean and standard deviation of the weights were equal.

GAA TTC CCT GGG TGA GAA and 3'- ACA GGG GAG AAA TCG ATG ACA (Xia et al., 2001); IFN- $\gamma$ (104 bp), 5'TTC TTC AGC AAC AGC AAG GC and 3'- CGG ATG AGC TCA TTG AAT GC; and IL-12p40 (121 bp), 5'- TCT TTG TTC GAA TCC AGC GC and 3'- ACA TTC CCG CCT TTG CAT TG.

\section{Immunization with ovalbumin and oral administration of P-Dex}

The mice were weighed and divided into M1 (OVA(-)/ P-Dex(-)), M2 (OVA(+)/P-Dex(-)), and M3 (OVA(+)/P$\operatorname{Dex}(+))$ groups in such a way that the means and standard deviations of the weights would be the same across the groups $(n=5)$. The treatment schedule is presented in Figure 1. On days 1, 8 and 15, mice were immunized via an intraperitoneal injection with $10 \mu \mathrm{g}$ of ovalbumin (OVA, Grade V; Sigma, St. Louis, MO, USA) and $3 \mathrm{mg}$ aluminum hydroxide (Sigma) in $0.5 \mathrm{ml}$ PBS, or with PBS alone. On days 16 to 25, the M3 group was administered $2 \mathrm{mg}$ of PDex orally in $0.5 \mathrm{ml}$ distilled water, and the others were given distilled water alone. On day 26, mice were sacrificed. At this time, the splenocytes were isolated for the cell proliferation assays and the levels of cytokines and CD86 were evaluated.

\section{Statistical analysis}

Statistical significance between groups was determined using the Student's $t$-test. Significance was accepted at the level of $\mathrm{p}<0.05$.

\section{RESULTS}

The optimal conditions for chemical phosphorylation of Dex

We firstly treated Dex in PB at various temperatures and $\mathrm{pH}$. Figure 2 shows the anion exchange chromatography profiles of crude P-Dex prepared at different temperatures. Crude P-Dex produced by heating Dex at $80^{\circ} \mathrm{C}$ for $48 \mathrm{~h}$ did not adsorb to the column; however, almost all (>90\%) was absorbed when prepared at over $120^{\circ} \mathrm{C}$. Table 1 shows the phosphorus content of P-Dex. We found that the phosphorus content was increased at the higher temperatures and lower $\mathrm{pH}$. Based on our data, the optimum conditions for the chemical phosphorylation of Dex were found to be $24 \mathrm{~h}$ at $160^{\circ} \mathrm{C}$ and a $\mathrm{pH}$ of 5.0 .

\section{Mitogenic activity of P-Dex under various phosphorylation conditions \\ We next examined the mitogenic activity of P-Dex produced under various phosphorylation conditions in splenocytes (Figure 3A). P-Dex preparations generated by heating at temperatures greater than $140^{\circ} \mathrm{C}$ significantly enhanced mitogenesis when compared to intact Dex. As the}

Table 1. Phosphorus content of P-Dex prepared under various conditions

\begin{tabular}{cccc}
\hline $\begin{array}{c}\text { Heating } \\
\text { temperature }\left({ }^{\circ} \mathrm{C}\right)\end{array}$ & $\begin{array}{c}\text { Heating time } \\
(\mathrm{h})\end{array}$ & $\mathrm{pH}$ & $\begin{array}{c}\text { Phosphorus } \\
(\% \mathrm{wt} / \mathrm{wt})\end{array}$ \\
\hline 80 & 48 & 5.5 & $\mathrm{ND}$ \\
100 & 24 & 5.5 & 0.5 \\
120 & 24 & 5.5 & 1.5 \\
140 & 24 & 5.5 & 5.5 \\
160 & 24 & 5.5 & 6.0 \\
160 & 24 & 4.5 & 3.1 \\
160 & 24 & 5.0 & 6.8 \\
160 & 24 & 5.5 & 6.0 \\
160 & 24 & 6.0 & 5.6 \\
160 & 24 & 7.0 & 4.2 \\
160 & 24 & 8.0 & 2.6 \\
\hline
\end{tabular}

ND = Not Detected.

Phosphorus content was quantified using the method of Fiske and SubbaRow using $\mathrm{KH}_{2} \mathrm{PO}_{4}$ as a standard. 

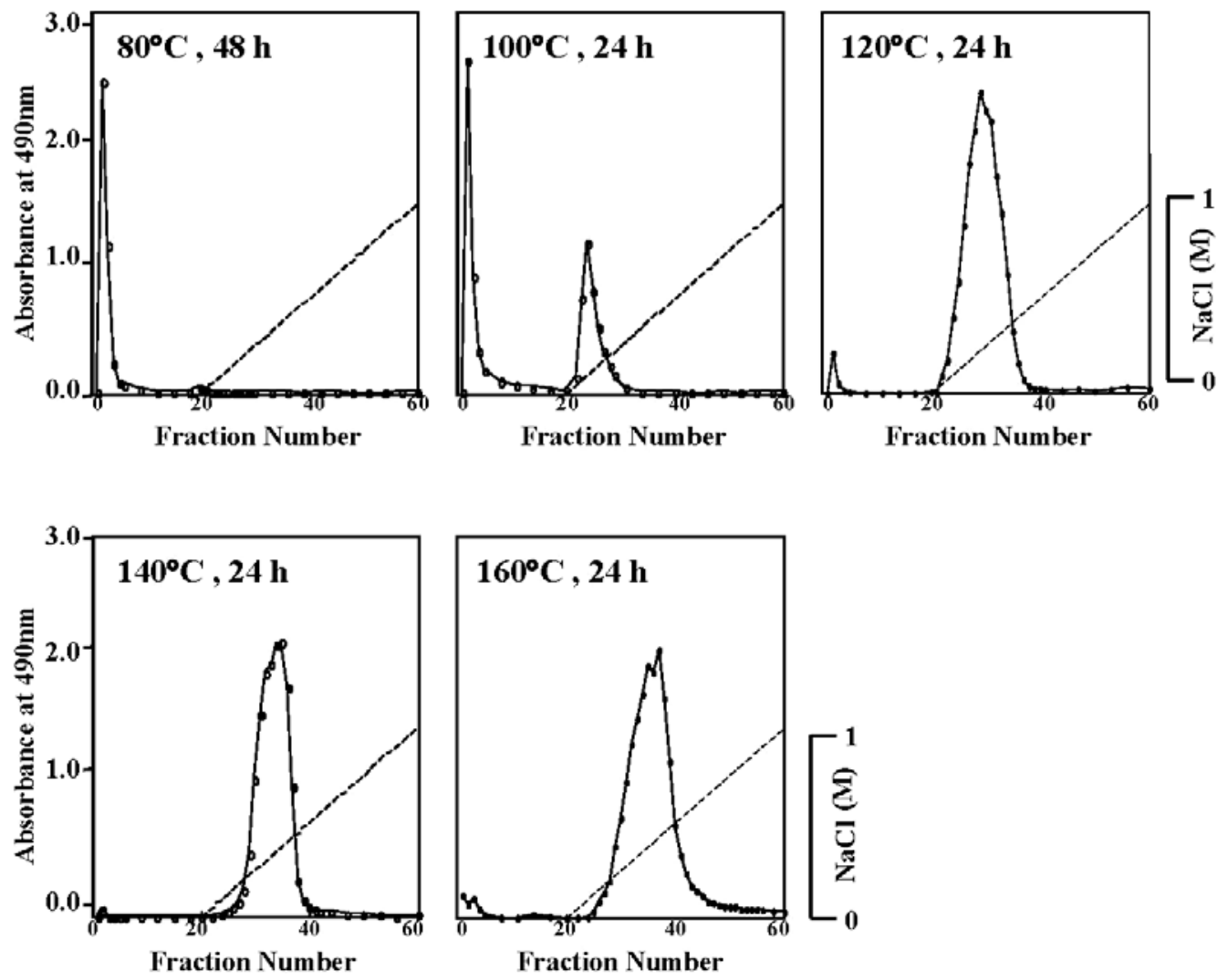

Figure 2. Elution profiles of the P-Dex obtained using anion exchange chromatography after phosphorylation. P-Dex was prepared by heating at $80^{\circ} \mathrm{C}$ for $48 \mathrm{~h}$ or $100^{\circ} \mathrm{C}, 120^{\circ} \mathrm{C}, 140^{\circ} \mathrm{C}$ or $160^{\circ} \mathrm{C}$ for $24 \mathrm{~h}$. P-Dex was eluted in a linear gradient of $\mathrm{NaCl}$ from 0 to $1.0 \mathrm{M}$, and the carbohydrate content of the eluate was measured at $490 \mathrm{~nm}$.

A.

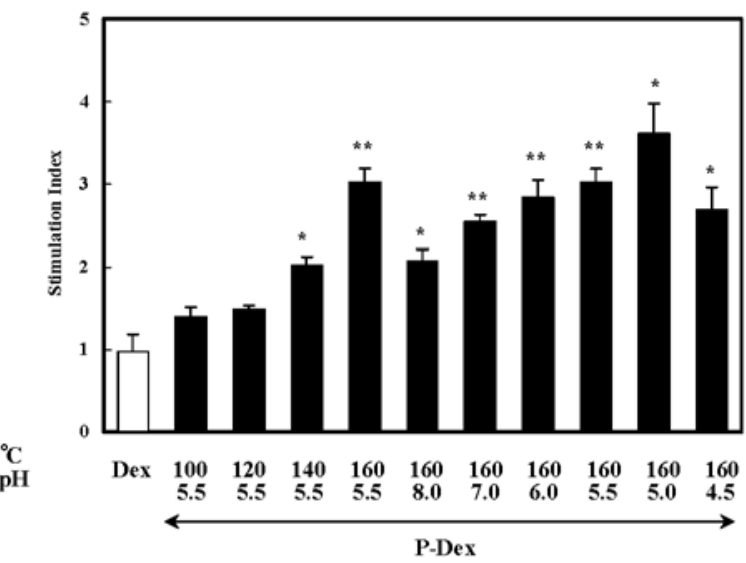

B.

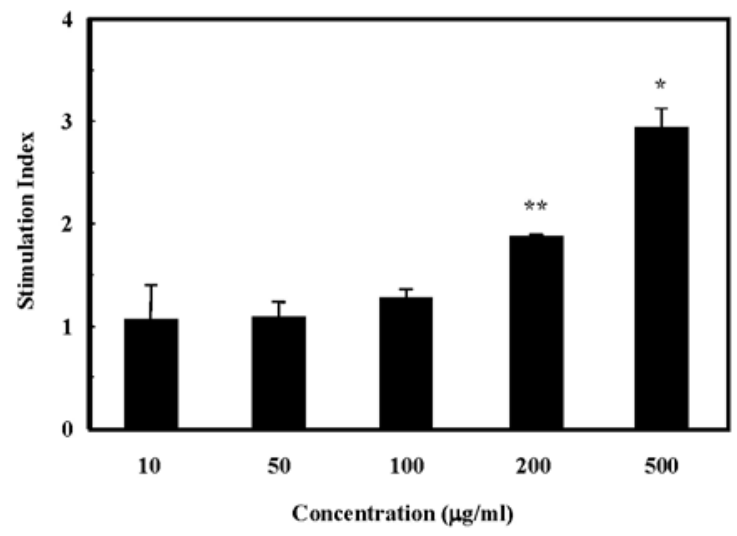

Figure 3. (A) Mitogenic activity of P-Dex in mouse splenocytes under various phosphorylation conditions. Open and filled bars indicate the mean stimulation index (SI) of Dex and P-Dex $(n=3)$, respectively. The results are presented as mean \pm standard deviation. The SI values of LPS and concanavalin A were 37.6 and 74.7, respectively. ${ }^{*} \mathrm{p}<0.05$, ${ }^{* *} \mathrm{p}<0.01$ vs. non-treated mice. (B) Dose response pattern of P-Dex-induced mitogenic activity. Following stimulation with P-Dex (10 to $500 \mu \mathrm{g} / \mathrm{ml})$, the cultures were pulsed with [ $\left.{ }^{3} \mathrm{H}\right] \mathrm{TdR}$ and the level of $\left[{ }^{3} \mathrm{H}\right] \mathrm{TdR}$ incorporated into the cells calculated. ${ }^{*} \mathrm{p}<0.05,{ }^{* *} \mathrm{p}<0.01$ vs. non-treated mice. 
highest mitogenic activity ( $\mathrm{SI}=3.6$ ) was observed using $\mathrm{P}$ Dex generated by heating for $24 \mathrm{~h}$ at $160^{\circ} \mathrm{C}$ and at $\mathrm{pH} 5.0$, we used this preparation in all further experiments. Mitogenic activity was found to increase in a dosedependent manner when treated with $200(\mathrm{SI}=3.0)$ to 500 $\mu \mathrm{g} / \mathrm{ml}(\mathrm{SI}=4.4)$ P-Dex (Figure $3 \mathrm{~B}$ ). In order to analyze the mitogenic properties of P-Dex, murine splenocytes were fractionated into B and T cells using a magnetic cell sorting system. We found that treatment with P-Dex induced significant proliferation of the B cell fraction $(\mathrm{SI}=2.5)$ but not the $\mathrm{T}$ cell fraction (SI = 1.1) (data not shown).

\section{P-Dex induces CD69/CD86 expression in vitro}

In order to precisely identify the cell types stimulated by P-Dex, we examined the expression of CD69 and CD86 on the surface of mouse splenocytes (Figure 4). After

A.
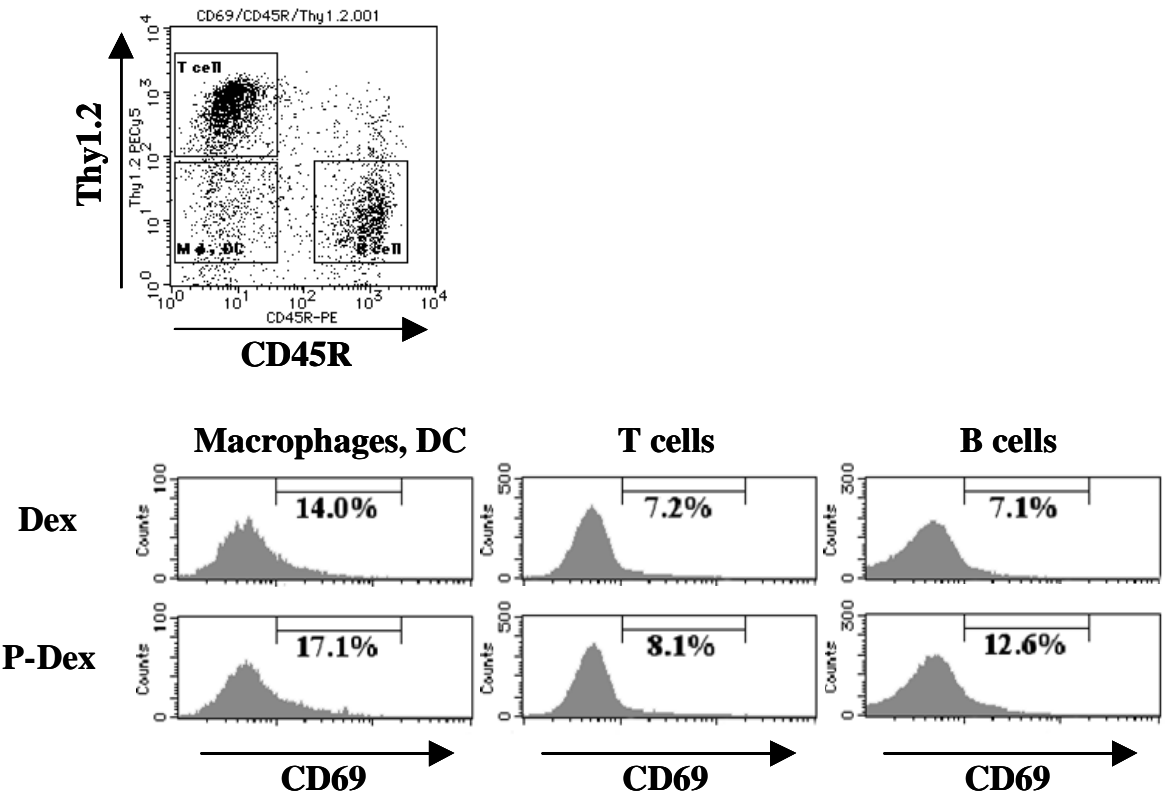

B.
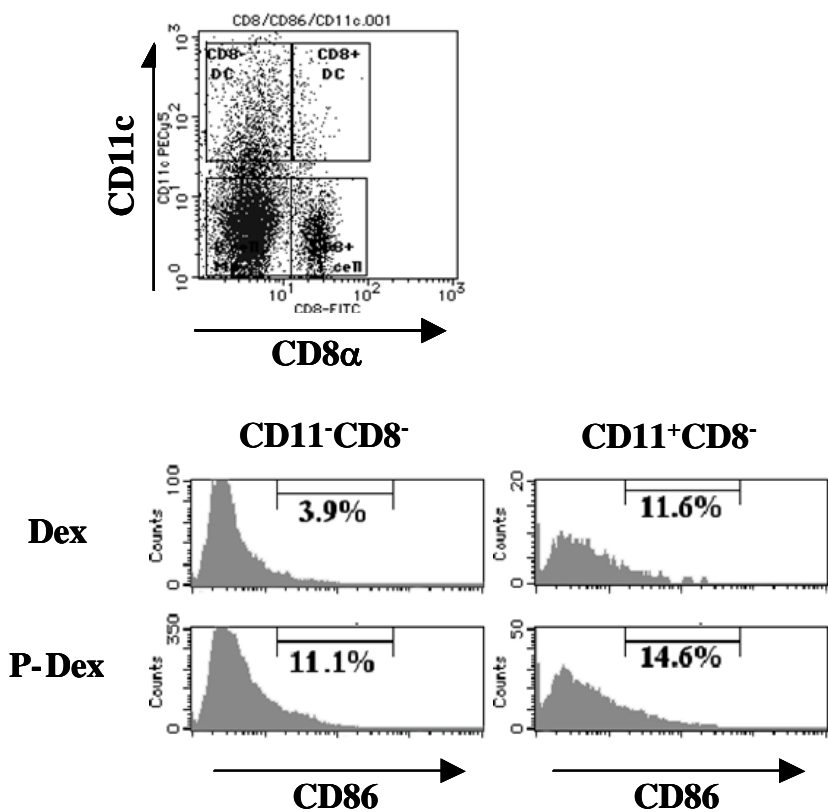

$\mathrm{CD11}^{+} \mathrm{CDB}^{+}$
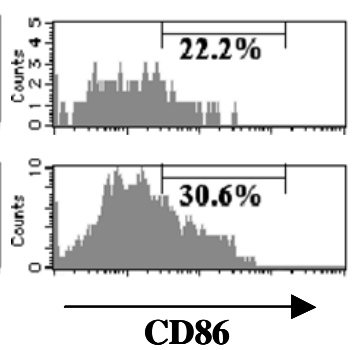

Figure 4. The expression of CD69 and CD86 on the surface of murine macrophages, DC, T cells and B cells following P-Dex stimulation for 6 and 24 h, respectively. (A) Cells were sorted into macrophages/DC (CD45R ${ }^{-}$Thy1.2 ), T cells (CD45R ${ }^{-}$Thy1.2 ${ }^{+}$), and B cells (CD45R ${ }^{+}$Thy1.2-) based on CD45R and Thy1.2 expression, and the percentage of CD69-positive cells determined in each group.

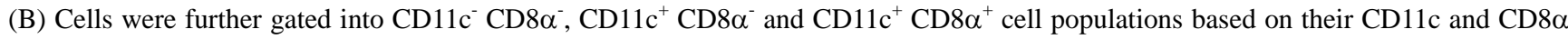
expression levels described in the text. 


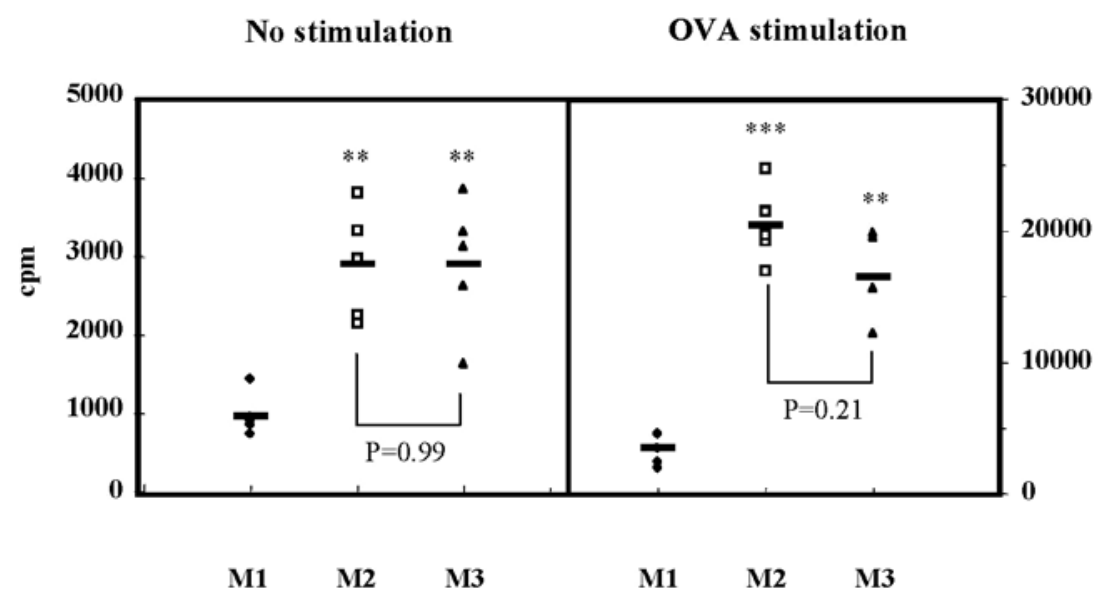

Figure 5. The effects of oral P-Dex administration on antigen-induced cell proliferation in OVA-stimulated splenocytes from the M1-M3 mouse groups. Splenocytes isolated from M1, M2 and M3 groups were stimulated for $48 \mathrm{~h}$ with or without OVA. * $\mathrm{p}<0.05, * * \mathrm{p}<0.01$, and ${ }^{* * *} \mathrm{p}<0.001$ vs. M1 group. M1 (OVA(-)/P-Dex(-)): solid diamonds, M2 (OVA(+)/P-Dex(-)): open squares and M3 (OVA(+)/PDex $(+))$ : solid triangles.

determining CD45R and Thy1.2 expression, the cells were divided into three groups based on their expression of surface antigens: i) macrophages/DC (CD45R ${ }^{-}$Thy1.2), ii) T cells (CD45R- Thy1.2 ${ }^{+}$) and iii) B cells (CD45R ${ }^{+}$Thy1.2-). As shown in Figure 4A, the highest induction of CD69 expression following treatment with P-Dex was observed in the B cell group. P-Dex administration resulted in only a slight increase in CD69 levels in the macrophage/DC and T cell groups. These results suggest that P-Dex may act as a B cell mitogen.

We also examined the expression of CD86 in cells gated into three groups based on their CD11c and CD8 $\alpha$ expression: i) CD11c $\mathrm{CD}^{-} \alpha^{-}$cells, ii) $\mathrm{CD} 11 \mathrm{c}^{+} \mathrm{CD} 8 \alpha^{-} \mathrm{DC}$,

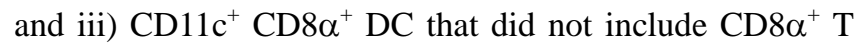
cells. The expression of CD86 in all three groups was found to be increased following P-Dex treatment (Figure 4B). Spleen-derived DC (CD11 $\mathrm{c}^{+}$cells) were further divided into Th1 $\left(\mathrm{CD}_{11 \mathrm{c}^{+}} \mathrm{CD} 8 \alpha^{+}\right)$and Th2 $\left(\mathrm{CD} 11 \mathrm{c}^{+} \mathrm{CD} 8 \alpha^{-}\right)$groups according to their $\mathrm{CD} 8 \alpha$ expression as reported previously (Maldonado-López et al., 1999; Iliev et al., 2008). We found that P-Dex treatment resulted in the stimulation of both Th1 and Th2 splenocyte proliferation in vitro.

\section{Immune regulation following oral administration of P-Dex}

We next analyzed antigen-induced cell proliferation in response to exogenous OVA stimulation in mouse splenocytes isolated from the M1, M2 and M3 mouse groups. We found that in the absence of exogenous OVA, splenocyte proliferation in the M2 and M3 groups was almost identical. When stimulated with exogenous OVA in vitro, the proliferation of splenocytes in the M2 group was strongly increased compared to M1 control group, whereas proliferation in the M3 group decreased by $23.1 \%$ when compared to the M2 group (Figure 5).

We also analyzed the expression of CD86 in splenocytes following treatment for $18 \mathrm{~h}$ at $37^{\circ} \mathrm{C}$ with or without OVA (Figure 6). The cells were divided into four groups based on their surface expression of $\mathrm{CD} 11 \mathrm{c}$ and $\mathrm{CD} 8 \alpha$ and were

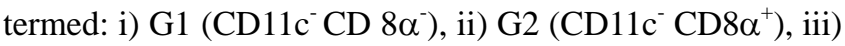
G3 (CD11c $\left.{ }^{+} \mathrm{CD} 8 \alpha^{-}\right)$and iv) G4 (CD11c $\left.{ }^{+} \mathrm{CD}^{+} \alpha^{+}\right)$cells. CD86 surface expression was examined for the G1, G3 and G4 cells, but not for G2 cells (CD8 $\alpha^{+} \mathrm{T}$ cells). We concentrated our analysis on the Th1 (G4) and Th2 (G3) cell populations (Maldonado-López et al., 1999; Iliev et al., 2008). In the G3 group, the expression of CD86 on splenocytes that did not receive exogenous OVA stimulation did not demonstrate any significant differences with the M1 group. In contrast, CD86 expression tended to be suppressed in the M3 group that did receive exogenous OVA stimulation $(p=0.56)$. In the $G 4$ cell population, CD86 expression did not appear to be changed in any of the treatment groups. These results demonstrate that OVA and P-Dex cause distinct changes in CD86 expression in G3 and G4 DC. In addition, we found that P-Dex was able to regulate Th2 cell population.

We also analyzed the expression of murine cytokines following stimulation of splenocytes from the M1-M3 groups of mice receiving exogenous OVA (Figure 7). We found that the expression of interferon gamma (IFN- $\gamma$ ) and interleukin 10 (IL-10) were induced in the M3 group following exogenous OVA stimulation. IL-12p40 expression was also induced in the M3 group that did not receive exogenous OVA, while there was no significant difference with the exogenous OVA-stimulated group. In addition, the expression of IL-4 was found to be suppressed 
G3

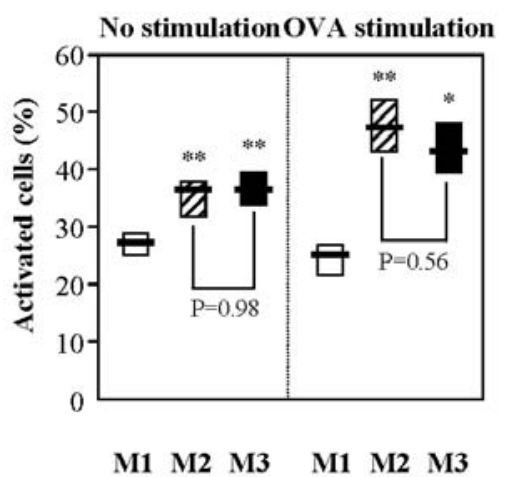

G4

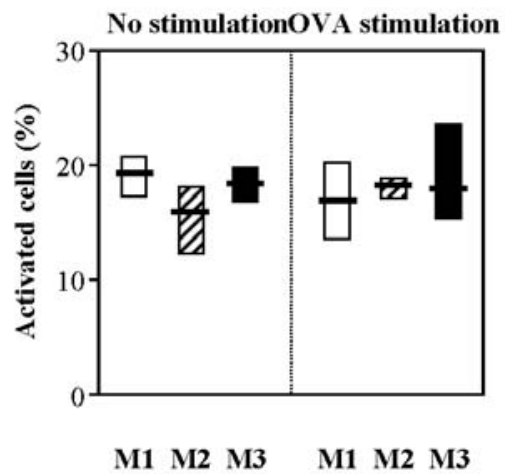

Figure 6. The effects of oral P-Dex administration on the expression of CD86 in OVA-stimulated splenocytes from the M1-M3 mouse groups. Splenocytes were stimulated with or without OVA for $18 \mathrm{~h}$ at $37^{\circ} \mathrm{C}$. The cells were triple-stained with PE-conjugated anti-CD86 $\mathrm{mAb}$, FITC-conjugated anti-CD8 $\alpha \mathrm{mAb}$ and biotinylated anti-CD11c mAb following incubation with PE-Cy5-conjugated streptavidin. The cells were then analyzed using two-color flow cytometry to detect the expression of CD8 $\alpha$ and CD11c on the splenocytes. Splenocytes were sorted into two groups and were termed G3 (CD11 $\left.{ }^{+} \mathrm{CD} 8 \alpha^{-}\right)$and G4 $\left(\mathrm{CD} 11 \mathrm{c}^{+} \mathrm{CD} 8 \alpha^{+}\right)$. The expression of CD86 was evaluated by the fluorescence intensity. M1 (OVA(-)/P-Dex(-)): open bars, M2 (OVA(+)/P-Dex(-)): hatched bars and M3 (OVA(+)/P$\operatorname{Dex}(+))$ : black bars. ${ }^{*} \mathrm{p}<0.05,{ }^{* *} \mathrm{p}<0.01$ vs. mice treated only with OVA and mice treated with both OVA and P-Dex, respectively.

in the M3 group following exogenous OVA stimulation when compared to the M2 group. Cytokine gene expression in the group of mice sacrificed on day 30 is also analyzed (data not shown). When comparing the cells isolated on days 26 and 30, we found that the expression of IFN- $\gamma$, IL-4 and IL-10 was induced in the M1 group stimulated with exogenous OVA on day 30. On day 26, the level of IFN- $\gamma$ in the splenocytes stimulated with exogenous OVA in the M3 group was highest, and was similar to the level observed in

No stimulation OVA stimulation

IFN- $\gamma$

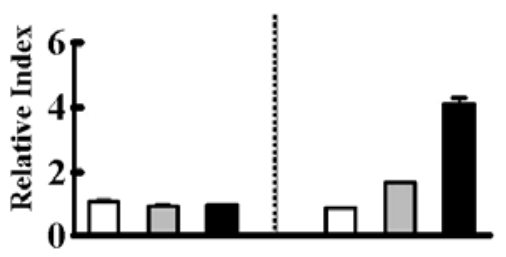

IL-12p40

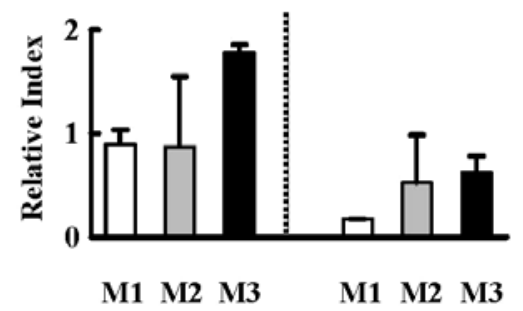

the M2 group on day 30. Furthermore, IL-10 levels were significantly induced in the M3 group treated with exogenous OVA on day 30.

\section{DISCUSSION}

We have previously reported that the phosphate groups present in APS play an important role in immunostimulation (Kitazawa et al., 1998). We prepared
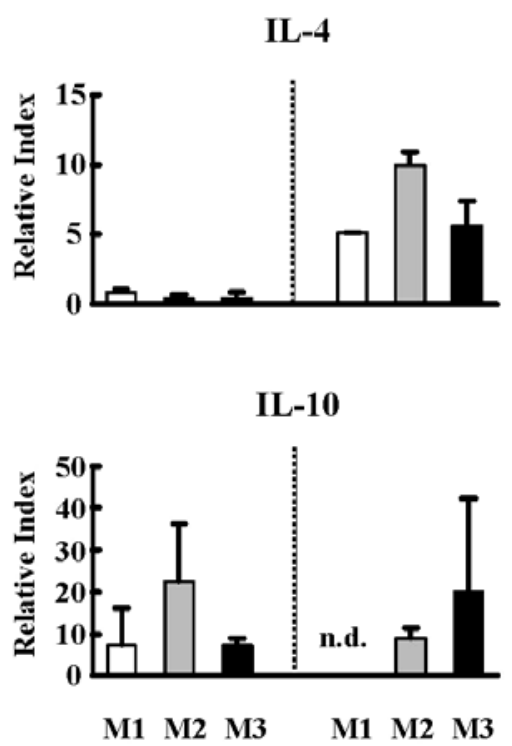

Figure 7. Cytokine mRNA levels in OVA-stimulated splenocytes from the M1-M3 mouse groups. The splenocytes were treated for $6 \mathrm{~h}$ with or without OVA and analyzed using real-time PCR. M1 (OVA(-)/P-Dex(-)): open bars, M2 (OVA(+)/P-Dex(-)): gray bars and M3 $(\mathrm{OVA}(+) / \mathrm{P}-\mathrm{Dex}(+))$ : black bars. 
APS from commercially available Dex that does not exhibit any physiological activity to demonstrate regulation of the immune response and to characterize the phosphorus groups of phosphopolysaccharides. As a result of these studies, we hypothesized that the phosphorus content of Dex correlates with the immunostimulatory effects. However, the previously published protocols used for the synthesis of P-Dex utilized toxic reagents including polyphosphoric acid and formamide, and resulted in a phosphorus content of P-Dex that was not as high as other bacterial phosphopolysaccharides. In the current study, we succeeded in synthesizing P-Dex efficiently and with a low toxicity using a modification of the method reported by Tarelli et al. (1994) that employed only phosphate buffer. We revealed that the phosphorylation efficiency of Dex was increased by adjusting both the reaction temperature and $\mathrm{pH}$. $\mathrm{Li}$ et al. (2003) reported that egg white protein may be phosphorylated using the same method, and that phosphorylation was promoted by decreasing the $\mathrm{pH}$ and increasing the temperature. It appears that the mechanisms underlying these phosphorylation reactions involve the removal of moisture from the reactive system by promoting a simple dehydration reaction. This reaction results in the formation of an ester bond between the phosphate group and the substrate, regardless of the target molecule. When polysaccharides are used as the target molecule, both the structure and the concentration ratio of the phosphate group to the substrate may also be important.

We next identified the physiological function of P-Dex in vitro including its effects on the induction of cell surface antigens. The results of magnetic cell sorting and fluorescence-activated cell sorting indicated that P-Dex functions a B cell-specific mitogen. It appeared that the immunopotentiating ability of P-Dex was largely due to the up-regulation of CD69 and CD86 on the surface of B cells and antigen-presenting cells including DC and macrophages. The results of this study are similar to those of previous studies (Sato et al., 2004). Recently, bacterial polysaccharides including lipopolysaccharide (LPS) and lipoteichoic acid have been shown to induce maturation and activation of DC via the toll-like receptors (TLR) 2 and 4, in addition to producing numerous proinflammatory cytokines (Michelsen et al., 2001; Geisel et al., 2007; Yanagawa and Onoé, 2007). Further studies are required to determine whether ligand recognition and signaling of P-Dex occurs via TLR.

In order to investigate the precise mechanisms underlying P-Dex activity, we examined whether oral administration of P-Dex regulated immune response in an allergic mouse model. In this model, mice were immunized with OVA using aluminum hydroxide as an adjuvant. The results of the in vivo studies revealed that oral administration of P-Dex enhanced mRNA expression levels of IFN- $\gamma$, whereas it suppressed the expression of IL-4. Furthermore, the induction of IFN- $\gamma$ expression was lost by day 30. Based on these results, it appears that the effects of P-Dex on Th1 induction are weak and tend to be lower as the time in culture increases. In contrast, P-Dex was found to strongly induce the expression of IL-10 on day 26, an effect that remained unchanged until day 30. In addition, P-Dex suppressed the antigen-induced response to exogenous OVA in the OVA-immunized mouse splenocytes. These results suggest that P-Dex regulates immune response via the induction of regulatory cytokines including IL-10.

Based on this data, we suggest that orally administered P-Dex reaches the small intestine, where it is incorporated into the GALT and is recognized as an antigen by DC located in the Peyer's patches. It is well established that the DC play an important role in the mucosal immune response. DC located at mucosal surfaces exhibit the specific capacity to induce differentiation of regulatory $\mathrm{T}$ cells, which results in the steady state production of IL-10. This response is thought to most likely involve CD11 $\mathrm{b}^{+}$DC and possibly even plasmacytoid DC (Kelsall, 2005). These DC are thought to be in an immature or altered state of activation and continuously present self-antigens, most likely acquired from cells undergoing apoptosis, for the induction and maintenance of self-tolerance (Steinman et al., 2003). Recently, it has also been shown that CD11b ${ }^{+}$DC mainly secrete IL-10 upon stimulation and induce Th3 cell differentiation. This Th3 cell immune response appears to be important for the induction of oral tolerance (Sato and Iwasaki, 2005). Based on these findings, P-Dex is thought to exert its effects through DC, which in turn are thought to be involved in regulatory $\mathrm{T}$ cell (Treg) activation. The identification of the mechanisms underlying P-Dex immunoregulation via Treg and DC, such as anti-allergic effects, need to be fully elucidated for P-Dex to be used in preventive or therapeutic applications in the future.

We conclude that P-Dex regulates the mucosal immune system and ameliorates allergic reactions. Further studies are required to increase our understanding of the mechanisms underlying recognition of P-Dex in the innate immune system. Recently, we have reported that $\mathrm{M}$ cells and immune cells located in the GALT express high levels of TLR (Tohno et al., 2005; Shimosato et al., 2007), and that one member of the TLR family recognizes phosphopolysaccharides produced by $L$. lactis subsp. cremoris (Tohno et al., 2007b). We have also reported that an immunostimulatory oligonucleotide from Bifidobacterium longum BB 536 improved Th1/Th2 balance via TLR 9 in mice (Takahashi et al., 2006a; 2006b; 2006c). We plan to examine whether P-Dex induces immune response via TLR in GALT in the future. These studies may aid in the development of foods that regulate 
immunological functions in allergic diseases.

\section{ACKNOWLEDGMENTS}

The authors wish to thank Mr. Daisuke Kurosaki and Mr. Shin-ichiro Kato for their technical help and their assistance with analysis. This study was partially supported by a Grant-in-Aid for Scientific Research (C) (no. 17580233) from the Japan Society for the Promotion of Science (JSPS).

\section{REFERENCES}

Colbère-Garapin, F., S. Martin-Latil, B. Blondel, L. Mousson, I. Pelletier, A. Autret, A. François, V. Niborski, G. Grompone, G. Catonnet and A. van de Moer. 2007. Prevention and treatment of enteric viral infections: possible benefits of probiotic bacteria. Microbes Infect. 9:1623-1631.

Dittmer, J. C. and M. A. Wells. 1969. Quantitative and qualitative analysis of lipids and lipid components. Meth. Enzymol. 14:482-530

Geisel, J., F. Kahl, M. Müller, H. Wagner, C. J. Kirsching, I. B. Autenrieth and J. S. Frick. 2007. IL-6 and maturation govern TLR2 and TLR4 induced TLR agonist tolerance and crosstolerance in dendritic cells. J. Immunol. 179(9):5811-5818.

Iliev, I. D., M. Tohno, D. Kurosaki, T. Shimosato, F. He, M. Hosoda, T. Saito and H. Kitazawa. 2008. Immunostimulatory oligodeoxynucleotide containing TTTCGTTT motif from Lactobacillus rhamnosus GG DNA potentially suppresses OVA-specific IgE production in mice. Scand. J. Immunol. 67:370-376.

Ito, S., K. J. Ishii, M. Gursel, H. Shirotra, A. Ihata and D. M. Klinman. 2005. CpG oligodeoxynucleotides enhance neonatal resistance to Listeria infection. J. Immunol. 174:777-782.

Kelsall, B. L. and F. Leon. 2005. Involvement of intestinal dendritic cells in oral tolerance, immunity to pathogens, and inflammatory bowel disease. Immunol. Rev. 206:132-148.

Kitazawa, H., T. Yamaguchi and T. Itoh. 1992. B-cell mitogenic activity of slime products produced from slime-forming, encapsulated Lactococcus lactis ssp. cremoris. J. Dairy Sci. 75:2946-2951.

Kitazawa, H., T. Harata, J. Uemura, T. Saito, T. Kaneko and T. Itoh. 1998. Phosphate group requirement for mitogenic activation of lymphocytes by an extracellular phosphopolysaccharide from Lactobacillus delbrueckii ssp. bulgaricus. Int. J. Food Microbiol. 40:169-175.

Kitazawa, H., Y. Ishii, J. Uemura, Y. Kawai, T. Saito, T. Kaneko, K. Noda and T. Itoh. 2000. Augmentation of macrophage functions by an extracellular phosphopolysaccharide from Lactobacillus delbrueckii ssp. bulgaricus. Food Microbiol. 17:109-118.

Lehmann, J., S. Bellmann, S. Werner, R. Schröder, N. Schütze and G. Alber. 2001. IL-12p40-Dependent agonistic effects on the development of protective innate and adaptive immunity against Salmonella enteritidis. J. Immunol. 167:5304-5315.

Li, C. P., A. S. Salvador, H. R. Ibrahim, Y. Sugimoto and T. Aoki. 2003. Phosphorylation of egg white proteins by dry-heating in the presence of phosphate. J. Agric. Food Chem. 51:6808-6815.
Maldonado-López, R., T. De Smedt, B. Pajak, C. Heiman, K. Thielemans, O. Leo, J. Urbain, C. R. Maliszewski and M. Moser. 1999. Role of CD8 $\alpha^{+}$and CD8 $\alpha^{-}$dendritic cells in the induction of primary immune responses in vivo. J. Leukoc. Biol. 66:242-246.

Michelsen, K. S., A. Aicher, M. Mohaupt, T. Hartung, S. Dimmeler, C. J. Kirschning and R. R. Schumann. 2001. The role of toll-like receptors (TLRs) in bacteria-induced maturation of murine dendritic cells (DCS). Peptidoglycan and lipoteichoic acid are inducers of DC maturation and require TLR2. J. Biol. Chem. 276(28):25680-25686.

Nishimura-Uemura, J., H. Kitazawa, Y. Kawai, T. Itoh, M. Oda and T. Saito. 2003. Functional alteration of murine macrophages stimulated with extracellular polysaccharides from Lactobacillus delbrueckii ssp. bulgaricus OLL1073R-1. Food Microbiol. 20:267-273.

Sato, A. and A. Iwasaki. 2005. Peyer's patch dendritic cells as regulators of mucosal adaptive immunity. Cell Mol. Life Sci. 62:1333-1338

Sato, T., J. Nishimura-Uemura, T. Shimosato, Y. Kawai, H. Kitazawa and T. Saito. 2004. Dextran from Leuconostoc mesenteroides Augments Immunostimulatory effects by the introduction of phosphate groups. J. Food Protect. 67:17191724.

Shimosato, T., H. Kitazawa, S. Katoh, Y. Tomioka, R. Karima, S. Ueha, Y. Kawai, T. Hishinuma, K. Matsushima and T. Saito. 2003. Swine Toll-like receptor 9 recognizes CpG motifs of human cell stimulant. Biochim. Biophys. Acta. 1627:56-61.

Steinman, R. M., D. Hawiger and M. C. Nussenzweig. 2003. Tolerogenic dendritic cells. Annu. Rev. Immunol. 3:685-711.

Suzuki, M., T. Mikami, T. Matsumoto and S. Suzuki. 1977. Preparation and antitumor activity of o-palmitoyldextran phosphates, o-palmitoyldextrans, and dextran phosphate. Carbohydr. Res. 53:223-229.

Takahashi, N., H. Kitazawa, T. Shimosato, N. Iwabushi, J. Z. Xiao, K. Iwatsuki, S. Kokubo and T. Saito. 2006a. An immunostimulatory DNA sequence from a probiotic strain of Bifidobacterium longum inhibits IgE production in vitro. FEMS Immunol. Med. Microbiol. 46:461-469.

Takahashi, N., H. Kitazawa, N. Iwabushi, J. Z. Xiao, K. Miyaji, K. Iwatsuki and T. Saito. 2006b. Immunostimulatory oligodeoxynucleotide from Bifidobacterium longum suppresses Th2 immune responses in a murine model. Clin. Exp. Immunol. 145:130-138.

Takahashi, N., H. Kitazawa, N. Iwabuchi, J. Z. Xiao, K. Miyaji, K. Iwatsuki and Tadao Saito. 2006c. Oral administration of an immunostimulatory DNA sequence from Bifidobacterium longum improves Th1/Th2 balance in a murine model. Biosci. Biotechnol. Biochem. 70:2013-2017.

Tarelli, E. and S. F. Wheeler. 1994. Drying from phosphatebuffered solutions can result in the phosphorylation of primary and secondary alcohol groups of saccharides, hydroxylated amino acids, proteins, and glycoproteins. Anal. Biochem. 222:196-201.

Tohno, M., T. Shimosato, H. Kitazawa, S. Katoh, D. I. Iliyan, T. Kimura, Y. Kawai, K. Watanabe, H. Aso, T. Yamaguchi and T. Saito. 2005. Toll-like receptor 2 is expressed on the intestinal M cells in swine. Biochem. Biophys. Res. Commun. 330:547554 
Tohno, M., T. Shimosato, Y. Kawai, H. Aso, S. Ikegami, N. Taketomo, T. Saito and H. Kitazawa. 2007a. Advanced molecular immunoassay system for immunobiotic lactic acid bacteria using a transfectant of Toll-like receptor 2. Anim. Sci. J. 78:195-205.

Tohno, M., T. Shimazu, W. Ueda, D. Anzawa, H. Aso, J. Nishimura, Y. Kawai, Y. Saito, T. Saito and H. Kitazawa. 2007b. Molecular cloning porcine RP105/MD-1 involved in recognition of extracellular phosphopolysaccharides from Lactococcus lactis ssp. cremoris. Mol. Immunol. 44:25662577.
Uemura, J., T. Itoh, T. Kaneko and K. Noda. 1998. Chemical characterization of extracellular polysaccharide from Lactobacillus delbrueckii subsp. bulgaricus OLL 1073R-1. Milchwissenschaft 53:443-446.

Xia, D., A. Sanders, M. Shan, A. Bickerestaff and C. Orosz. 2001. Real-time polymerase chain reaction analysis reveals an evolution of cytokine mRNA production in allograft acceptor mice. Transplantation 72:907-914.

Yanagawa, Y. and K. Onoé. 2007. Enhanced IL-10 production by TLR4- and TLR2-primed dendritic cells upon TLR restimulation. J. Immunol. 178(10):6173-6180. 